\title{
Low-dose metronomic chemotherapy as an efficient treatment option in metastatic breast cancer-results of an exploratory case-control study
}

\author{
S. Krajnak ${ }^{1}$ (1) C. Schnatz ${ }^{1} \cdot$ K. Almstedt $^{1} \cdot$ W. Brenner ${ }^{1} \cdot$ F. Haertner ${ }^{2} \cdot$ A.-S. Heimes ${ }^{1} \cdot$ A. Lebrecht ${ }^{1} \cdot$ G.-M. Makris ${ }^{1}$. \\ R. Schwab ${ }^{1}$ - A. Hasenburg ${ }^{1} \cdot$ M. Schmidt ${ }^{1}$ - M. J. Battista ${ }^{1}$
}

Received: 10 April 2020 / Accepted: 26 May 2020 / Published online: 3 June 2020

(c) The Author(s) 2020

\begin{abstract}
Purpose There is growing interest in low-dose metronomic chemotherapy (LDMC) in metastatic breast cancer (MBC). In this retrospective case-control analysis, we compared the efficacy of LDMC and conventional chemotherapy (CCT) in MBC. Methods Each LDMC patient receiving oral cyclophosphamide (CTX) (50 mg daily) and methotrexate (MTX) (2.5 mg every other day) was matched with two controls who received CCT. Age, number of chemotherapy lines and metastatic sites as well as hormone receptor (HR) status were considered as matching criteria. Primary endpoint was disease control rate longer than 24 weeks (DCR). Secondary endpoints were progression-free survival (PFS), duration of response (DoR) and subgroup analyses using the matching criteria.

Results 40 cases and 80 controls entered the study. 30.0\% patients with LDMC and 22.5\% patients with CCT showed DCR $(p=0.380)$. The median PFS was 12.0 weeks in both groups $(p=0.218)$ and the median DoR was 31.0 vs. 20.5 weeks ( $p=0.383$ ), respectively. Among younger patients, DCR was $40.0 \%$ in LDMC vs. $25.0 \%$ in the CCT group $(p=0.249)$. DCR was achieved in $33.3 \%$ vs. $26.2 \%$ non-heavily pretreated patients $(p=0.568)$ and in $36.0 \%$ vs. $18.0 \%$ patients without multiple metastases $(p=0.096)$, respectively. In the HR-positive group, 30.0\% LDMC vs. 28.3\% CCT patients showed DCR $(p=1.000)$. Among triple-negative patients, DCR was achieved in 30.0\% LDMC and 5.0\% CCT patients $(p=0.095)$.

Conclusions We demonstrated a similar efficacy of LDMC compared to CCT in the treatment of MBC. Thus, LDMC may be a valuable treatment option in selected MBC patients.
\end{abstract}

\section{Introduction}

Metastatic breast cancer (MBC) is an incurable but treatable disease. Thus, it is crucial to achieve disease control with preservation of quality of life (QoL) [1]. In the last decades low-dose metronomic chemotherapy (LDMC) gained increasing popularity [2,3]. LDMC is defined as a continuous administration of cytotoxic drugs at low doses, distinctly lower than the maximum tolerable dose (MTD) of conventional chemotherapy (CCT) [4]. Consequently, compared to

S. Krajnak

slavomir.krajnak@unimedizin-mainz.de

1 Department of Gynecology and Obstetrics, University Medical Center Mainz, Langenbeckstrasse 1, 55131 Mainz, Germany

2 Institute of Medical Biometry, Epidemiology and Informatics (IMBEI), University Medical Center Mainz, Mainz, Germany
MTD the lower doses of chemotherapeutic drugs may induce less adverse events like myelosuppression, mucositis or hair loss [5-7]. It is assumed that LDMC is not simply a different way of administering chemotherapy but a truly new treatment option $[3,8,9]$. This alternative strategy has been used especially in elderly patients, not eligible for a CCT [8]. The orally available and well-established cytostatic agents like cyclophosphamide (CTX), methotrexate (MTX), vinorelbine (VRL) and capecitabine (CAPE) are suited for metronomic chemotherapy. The best experience about LDMC arises from phase II studies, however phase III studies are still lacking. Furthermore, to the best of our knowledge, there is insufficient experience regarding the efficacy of metronomic chemotherapy, compared to CCT in MBC.

In this retrospective case-control study, the efficacy of metronomic administered CTX/MTX and CCT was compared in matched pairs and subgroup analyses were performed to define patients in which LDMC might be a more effective treatment option. 


\section{Methods}

MBC patients receiving LDMC with oral CTX (50 mg daily) and MTX (2.5 mg every other day) at the Department of Gynecology and Obstetrics of the University Medical Center Mainz, Germany between 2009 and 2018 were selected for this retrospective analysis as previously described [10]. Each LDMC patient was matched with two patients, who received CCT, if matching criteria (measurable metastatic disease, age at start of therapy, number of chemotherapy lines and different metastatic sites as well as hormone receptor (HR) status) were met. No antiemetic treatment was routinely given to patients in the LDMC group. In the CCT group only patients without therapy termination due to toxicity were included. No concomitant treatment like radiotherapy, endocrine or targeted therapy was allowed. HER2-positive patients and patients with presence of additional cancer were excluded.

Primary endpoint was disease control rate longer than 24 weeks (DCR). DCR included stable disease (SD), partial response (PR) and complete response (CR). Secondary endpoints were progression-free survival (PFS), duration of response (DoR), as well as DCR and PFS in subgroups. The DoR was defined as the time from documentation of tumor response to progression disease (PD) or death. The therapy efficacy was assessed using the standard clinical and imaging methods. For subgroup analyses we used the a priori determined matching criteria to obtain comparable populations of same size. Thereby, we stratified the patients by age at start of LDMC/CCT (younger: $\leq$ median age vs. elderly: $>$ median age), the number of chemotherapy lines (non-heavily pretreated: $\leq 2$ chemotherapy lines vs. heavily pretreated: $>2$ chemotherapy lines), number of different metastatic sites (no multiple metastases: $\leq 2$ different metastatic sites vs. multiple metastases: $>2$ different metastatic sites) and by HR status (HR-positive: oestrogen/progesterone positive and HER2-negative vs. triple-negative). SPSS (statistical software system, version 23.0. IBM Corp., Armonk, NY, U.S.) was used for statistical analyses. Patient characteristics and therapy response (DCR and therapy response in subgroups) were analysed by applying a Fisher's Exact test. For PFS and DoR analysis Kaplan-Meier estimator was used. The Logrank test was used for the comparisons of survival curves between LDMC and CCT group. A Cox regression model was used to estimate the hazard ratio (HR) and $95 \%$ confidence interval (CI) in the analysis of PFS and DoR. All tests were two-sided and $p<0.05$ was considered as statistically significant. Written informed consent was obtained from all patients included in the study.

\section{Results}

\section{Patient characteristics}

In total, 120 patients ( 40 cases and 80 controls) entered the study. Patient characteristics are shown in Table 1. The median age at first diagnosis (FD) of MBC was 59 (33-82) years in the LDMC group and 59 (28-81) years in the CCT group $(p=0.544)$. The median age at start of therapy was 63 (range 35-83) years and 61 (range 30-81) years $(p=0.230)$, respectively. In the HR-positive cohort, 93.3\% LDMC patients and 71.7\% CCT patients had at least one endocrine therapy in MBC prior to LDMC or CCT treatment $(p=0.026) .47 .5 \%$ vs. $51.3 \%$ patients received adjuvant or neoadjuvant chemotherapy at FD of breast cancer (BC) $(p=0.847)$. After FD of MBC, 52.5\% patients received less than 2 chemotherapy lines before LDMC/CCT ( $p=1.000)$ (Table 1). 62.5\% patients had up to 2 different metastatic lesions $(p=1.000)$. In the LDMC group as well as in the CCT group 25.0\% patients showed triple-negative disease $(p=1.000)$. As demonstrated in Table 1, all matching criteria were met. The most frequent site of metastases in the LDMC group as well as in the CCT group were bone $(62.5 \%$ vs. $70.0 \%$, $p=0.417)$, liver $(52.5 \%$ vs. $52.5 \%, p=1.000)$ and lung ( $40 \%$ vs. $40 \%, p=1.000$ ), respectively. There were no significant differences regarding number and localization of metastatic lesions between the two groups (Table 2). In the CCT group, the most frequently used chemotherapy regimen was capecitabine $(27.5 \%)$ and pegylated liposomal doxorubicin $(26.3 \%)$. Taxanes were administered in $17.5 \%$ patients and eribulin in $12.5 \%$ patients (Table 3 ).

\section{Therapy response}

DCR was achieved in 30.0\% LDMC patients and in $22.5 \%$ CCT patients ( $p=0.380$ ) (Table 2). 12.5\%, 15.0\%, 2.5\% LDMC patients vs. $18.8 \%, 3.8 \%, 0.0 \%$ CCT patients showed SD, PR, CR, respectively (Table 4). The median PFS was 12.0 weeks (95\% CI 9.9-14.1) in the LDMC group, as compared with 12.0 weeks (95\% CI 10.5-13.5) in the CCT group, HR for progression or death was 0.796 ; 95\% CI 0.541-1.170; $p=0.245$ (Fig. 1). The median DoR was 31.0 weeks in the LDMC group and 20.5 weeks in the CCT group ( $p=0.383$ ) (Table 4$)$, HR for progression or death was $0.749 ; 95 \%$ CI $0.385-1.459 ; p=0.396$. Therapy response was detected in $37.5 \%$ LDMC patients and in $30.0 \%$ CCT patients $(p=0.417)$ (Table 4$)$. 


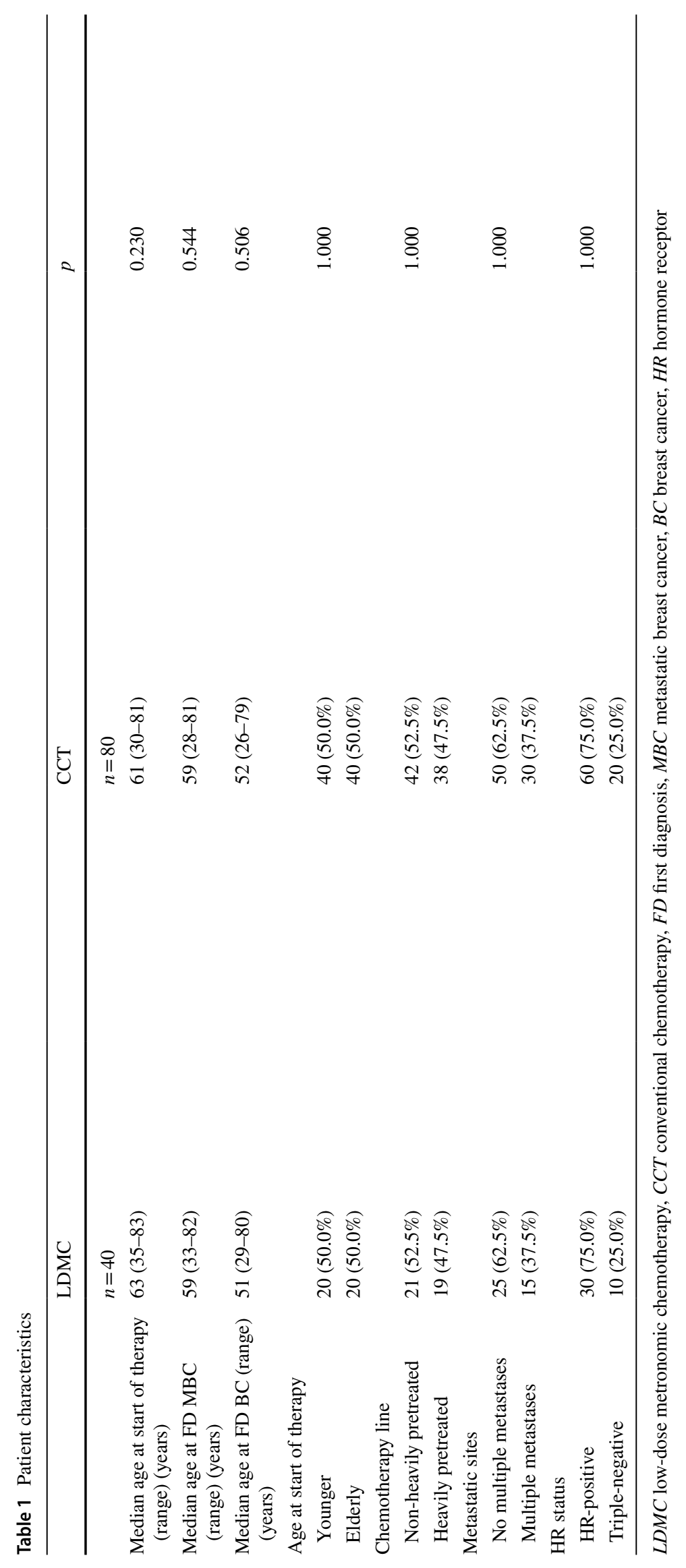




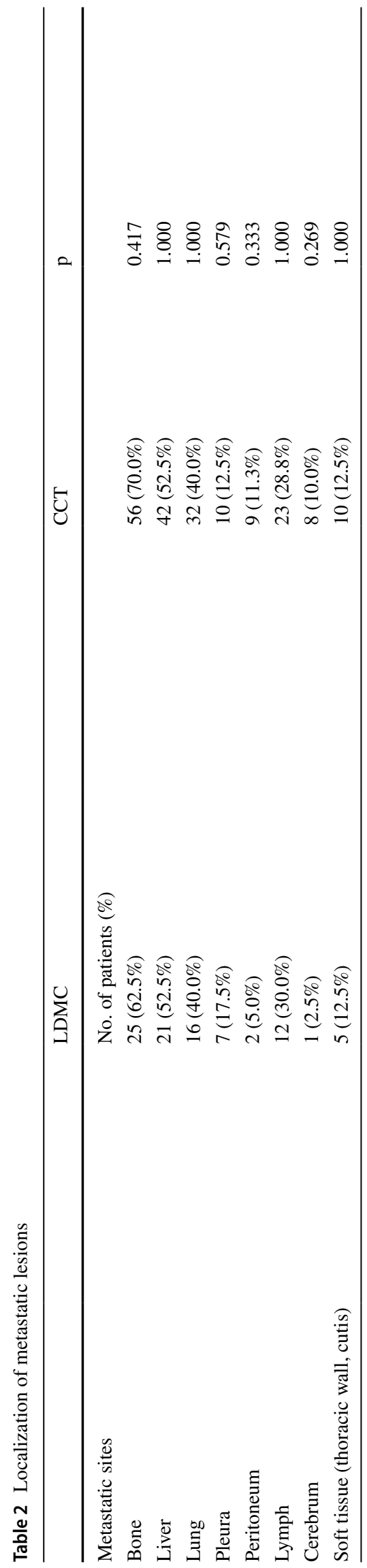

Table 3 Chemotherapeutic substances in the conventional chemotherapy group

\begin{tabular}{ll}
\hline Chemotherapy & No. of patients (\%) \\
\hline Capecitabine & $22(27.5 \%)$ \\
Pegylated liposomal doxorubicin & $21(26.3 \%)$ \\
Taxane (paclitaxel/nab-paclitaxel/doc- & $14(17.5 \%)(4(5.0 \%) / 8$ \\
$\quad$ etaxel) & $(10.0 \%) / 2(2.5 \%))$ \\
Eribulin & $10(12.5 \%)$ \\
Carboplatin + gemcitabine & $5(6.3 \%)$ \\
Vinorelbine & $4(5.0 \%)$ \\
Other (doxorubicin/carboplatin/fluoroura- & $4(5.0 \%)($ each 1 $1.3 \%))$ \\
cil/capecitabine + vinorelbine) & \\
\hline
\end{tabular}

\section{Therapy response in subgroups}

In the subgroup analyses, $40.0 \%$ younger LDMC patients and $25.0 \%$ younger CCT patients showed DCR $(p=0.249)$ (Fig. 2a). 20.0\% elderly patients achieved DCR in both treatment groups $(p=1.000)$. Among non-heavily pretreated patients, DCR was $33.3 \%$ in the LDMC and $26.2 \%$ in the CCT group $(p=0.568)$. In the heavily pretreated group, $26.3 \%$ vs. $18.4 \%$ patients showed DCR $(p=0.509)$. DCR was achieved in $36.0 \%$ LDMC patients and in $18.0 \%$ CCT patients $(p=0.096)$ without multiple metastases and in $20.0 \%$ vs. $30.0 \%$ with multiple metastases $(p=0.722)$. $30.0 \%$ vs. $28.3 \%$ HR-positive patients $(p=1.000)$ and $30.0 \%$ vs. $5.0 \%$ triple-negative patients achieved DCR $(p=0.095)$, respectively.

The median PFS in younger patients was 15.0 weeks in the LDMC group and 14.0 weeks in the CCT group $(p=0.212)$ (Fig. 2b), HR for progression or death was $0.719 ; 95 \% \mathrm{CI}$ $0.415-1.243 ; p=0.237$ (Fig. 2c). Elderly patients showed a median PFS of 12.0 weeks in both groups ( $p=0.627$ ) (Fig. 2b). The median PFS in non-heavily pretreated patients was 17.0 weeks vs. 15.0 weeks ( $p=0.531$ ) (Fig. 2b), HR for progression or death was $0.849 ; 95 \%$ CI $0.500-1.442 ; p=0.544$ (Fig. 2c). In the heavily pretreated subgroup, the median PFS was 12.0 weeks for both treatment groups $(p=0.235)$ (Fig. 2b). The median PFS in patients without multiple metastases was 16.0 weeks vs. 12.0 weeks ( $p=0.064$ ) (Fig. $2 b$ ), HR for progression or death was $0.642 ; 95 \%$ CI $0.392-1.053 ; p=0.079$ (Fig. 2c). In the cohort with multiple metastases, the median PFS was 12.0 weeks in both groups $(p=0.684)$ (Fig. 2b). Regarding receptor status, the median PFS was 12.0 weeks vs. 14.0 weeks in the HR-positive group $(p=0.570)$ and 12.0 weeks in both triple-negative groups ( $p=0.081)$ (Fig. 2b). 
Table 4 Therapy response

\begin{tabular}{|c|c|c|c|c|}
\hline & & $\begin{array}{l}\text { LDMC } \\
n=40\end{array}$ & $\begin{array}{l}\text { СCT } \\
n=80\end{array}$ & $p$ \\
\hline $\operatorname{DCR}(n(\%))$ & & $12(30.0 \%)$ & $18(22.5 \%)$ & 0.380 \\
\hline \multirow[t]{4}{*}{ Therapy response after 24 weeks } & PD & $28(70.0 \%)$ & $62(77.5 \%)$ & \\
\hline & SD & $5(12.5 \%)$ & $15(18.8 \%)$ & \\
\hline & PR & $6(15.0 \%)$ & $3(3.8 \%)$ & \\
\hline & $\mathrm{CR}$ & $1(2.5 \%)$ & $0(0.0 \%)$ & \\
\hline Median PFS (range) (weeks) & & $12.0(6-86)$ & $12.0(4-100)$ & 0.218 \\
\hline Median duration of response (range) (weeks) & & $31.0(12-74)$ & $20.5(12-88)$ & 0.383 \\
\hline Therapy response (n (\%)) & & $15(37.5 \%)$ & $24(30.0 \%)$ & 0.417 \\
\hline
\end{tabular}

$D C R$ Disease Control Rate, $P F S$ progression-free survival, $P D$ progression disease, $S D$ stable disease, $P R$ Partial response, $C R$ Complete response

\section{Discussion}

In this retrospective case-control study $120 \mathrm{MBC}$ patients were evaluated regarding the efficacy of the chemotherapy treatment. The primary endpoint DCR did not differ significantly between LDMC and CCT group (30.0\% vs. $22.5 \%$, $p=0.380$ ). The impact of metronomic CTX/MTX in our cohort of HR-positive and HER2-negative MBC patients as measured by DCR after 24 weeks of treatment was in line with previous studies [11-13]. Gebbia et al. [6] observed a higher PR rate in the cohort of patients with the combination CTX/MTX as compared to that treated with CTX alone ( $20 \%$ vs. $14 \%, p=0.45)$. The median PFS was 12.0 weeks in the LDMC as well as in the CCT group $(p=0.218)$. Furthermore, DoR (31.0 vs. 20.5 weeks, $p=0.383$ ) and therapy response $(37.5 \%$ vs. $30.0 \%, p=0.417)$ failed to show any significant differences between LDMC and CCT group. Moreover, the rate of treatment response may also depend on patient characteristics like age, metastatic spread, HR status as well as previous treatment. In the subgroup of younger patients, DCR was documented in $40.0 \%$ patients in the LDMC group and in $25.0 \%$ patients in the CCT group $(p=0.249)$. According to current recommendations for treatment of MBC, LDMC is primarily intended for elderly and frail patients, who are not suitable for conventional dosis of chemotherapy [14-16]. However, we have shown that LDMC can also be a treatment option for younger patients. Based on previous data from phase II studies, LDMC regimens provide promising results in the first-line setting with a clinical benefit rate (CBR) of up to $78 \%$ and a median time to progression (TTP) of up to 22 months [17-19]. Among the non-heavily pretreated subgroup, 33.3\% LDMC patients and $26.2 \%$ CCT patients showed DCR $(p=0.568)$. More importantly, it is well established that the duration of disease control decreases with the increasing number of chemotherapy lines [20]. In the subgroup without multiple metastases, LDMC patients showed DCR twice as often as in the control group (36.0\% vs. $18.0 \%, p=0.096)$ and the median PFS was
16.0 weeks vs. 12.0 weeks $(p=0.064)$ with a trend towards significance. In the HR-positive group, we found no differences in DCR between the two groups. However, among triple-negative patients, $30.0 \%$ patients with LDMC compared to $5.0 \%$ patients with CCT showed DCR $(p=0.095)$ resulting in a borderline significance in favor of LDMC. A beneficial effect of the metronomic combination of VRL and CAPE was also shown in the triple-negative subgroup (28 patients) in the VICTOR-2 study [21]. The DCR was 53.7\% and the median PFS was 4.7 months. Furthermore, LDMC with CTX/MTX was well-tolerable with almost only grade 1-2 toxicities. The most frequent adverse events were leukopenia (1-49\%), nausea/vomiting (3-39\%) and gastric pain (6-7\%). Elevated values of transaminases, observed in up to $60 \%$ patients (10\% grade $3-4)$, were mostly attributable to concomitant hepatic metastases or recovered with reduction or transient interruption of MTX [10, 12, 22]. In order to reduce hepatic toxicity and simplify the drug administration we modified the MTX schedule $(2.5 \mathrm{mg}$ every other day instead of $2.5 \mathrm{mg}$ twice a day on days 1 and 4 every week) and found no grade 3-4 hepatic toxicities [10].

By reference to current experience, endocrine-based therapy should be provided as the first choice for MBC with positive HR status except in the case of life-threating disease [23]. In the last decade, new options as cyclindependent-kinase (CDK) inhibitors and immune checkpoint inhibitors for the treatment of $\mathrm{MBC}$ were established [24-26]. Moreover, LDMC has gained increasing interest through its multi-targeted nature. In addition to direct cytotoxic effect, LDMC induces indirect effects on tumor cells by modulation of tumor microenvironment via inhibition of angiogenesis and stimulation of immune response [27-29]. Thus, while the anti-tumor response to LDMC may be delayed, the effect is more likely to be sustained, owing to the decreased selection of resistant tumor cell clones and the suppression of anti-tumour immunity with a decreased likelihood of disease relapse [30]. Oral administration of well-tolerable LDMC including improvement 
Fig. 1 Kaplan-Meier analysis of progression-free survival. a all patients: median PFS in LDMC and CCT: 12.0 weeks vs. 12.0 weeks, Log-rank: $p=0.218$. b younger patients: median PFS in LDMC and CCT: 15.0 weeks vs. 14.0 weeks, Log-rank: $p=0.212$. c non-heavily pretreated patients: median PFS in LDMC and CCT: 17.0 weeks vs. 15.0 weeks, Log-rank: $p=0.531$. d patients without multiple metastases: median PFS in LDMC and CCT: 16.0 weeks vs. 12.0 weeks, Log-rank: $p=0.064$. e HRpositive patients: median PFS in LDMC and CCT: 12.0 weeks vs. 14.0 weeks, Log-rank: $p=0.570$. f triplenegative patients: median PFS in LDMC and CCT: 12.0 weeks vs. 12.0 weeks, Log-rank: $p=0.081$. LDMC low-dose metronomic chemotherapy), $C C T$ conventional chemotherapy
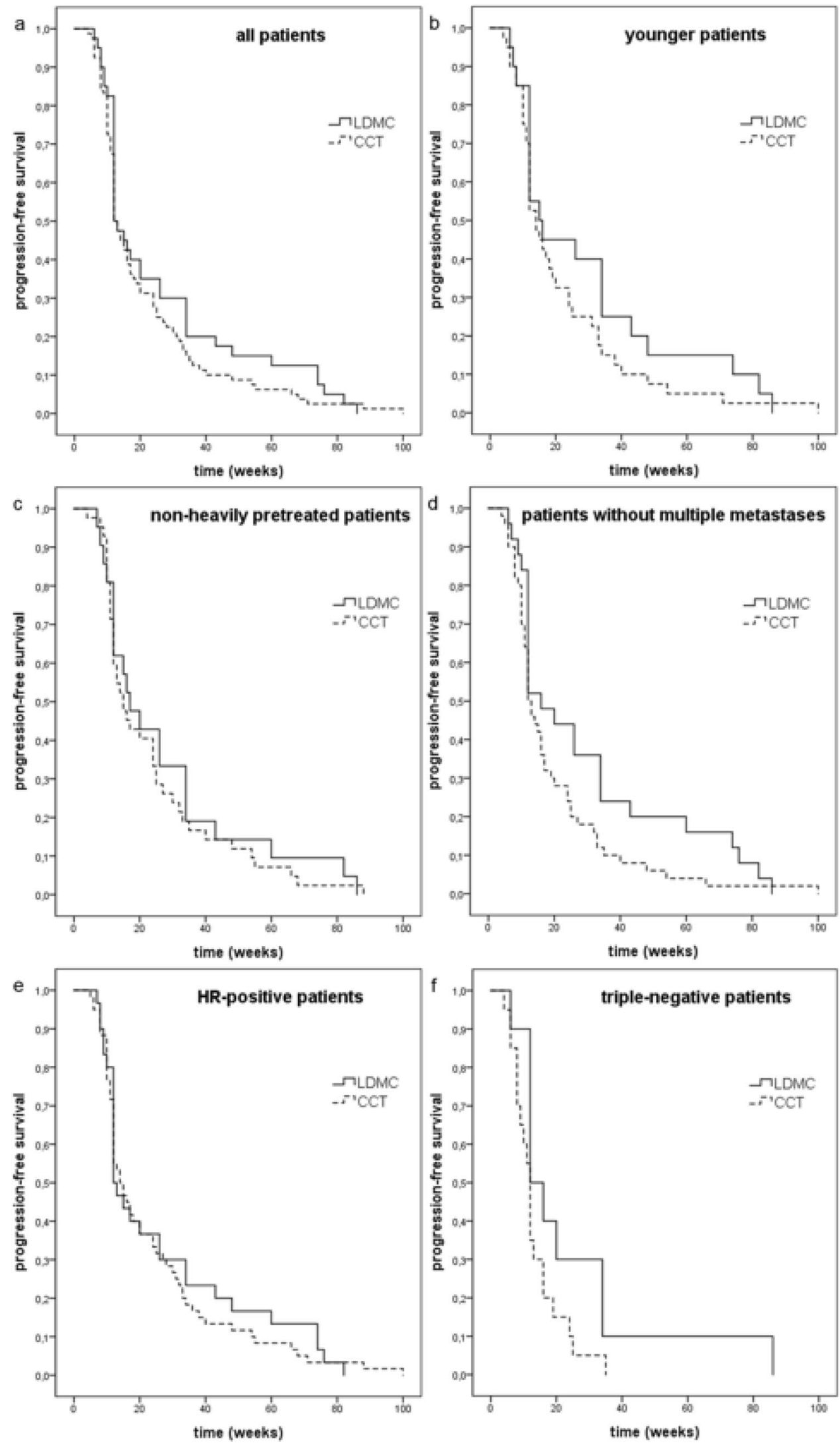
a

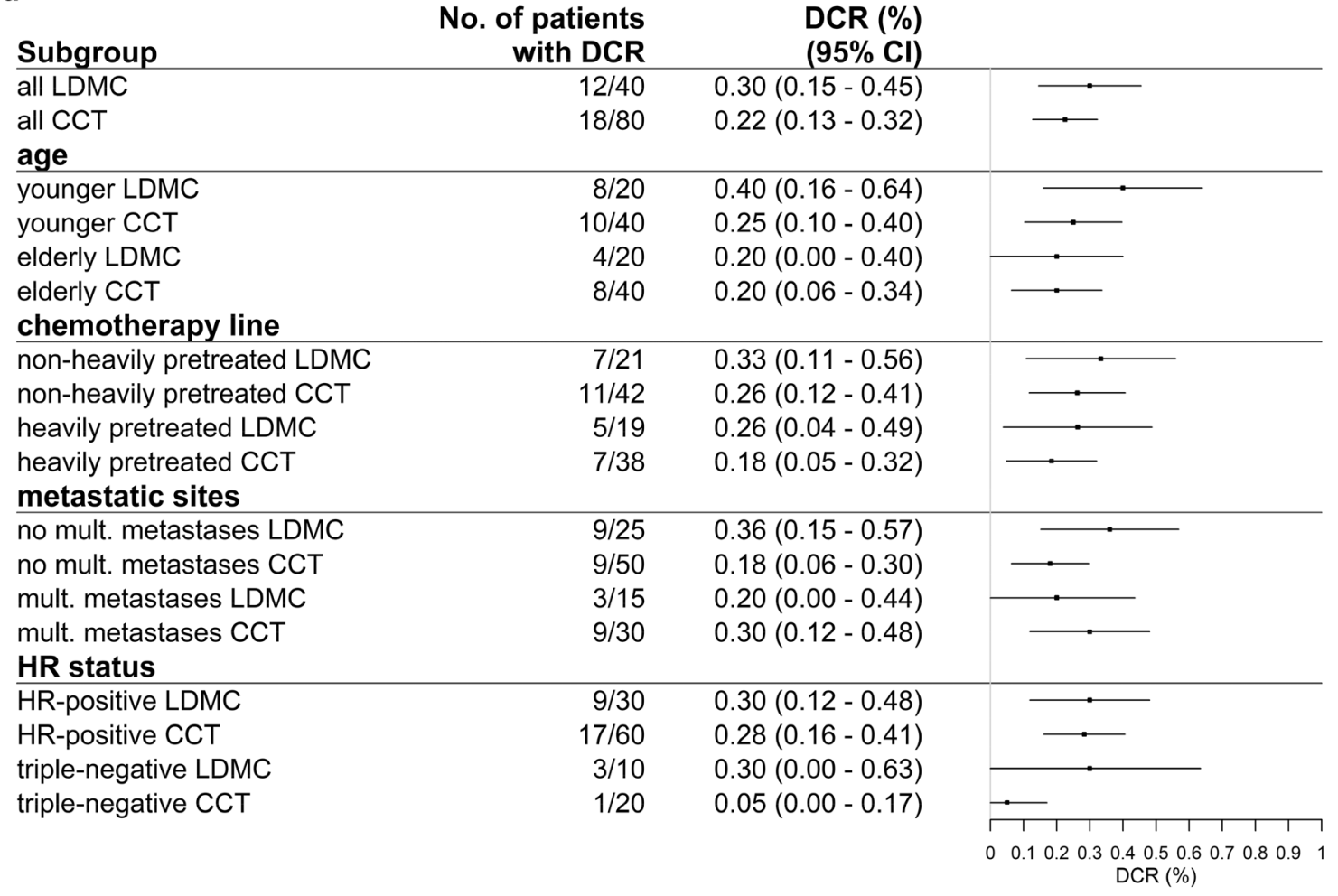

b

median progressionfree survival (weeks)

Subgroup No. of patients $(95 \% \mathrm{Cl})$

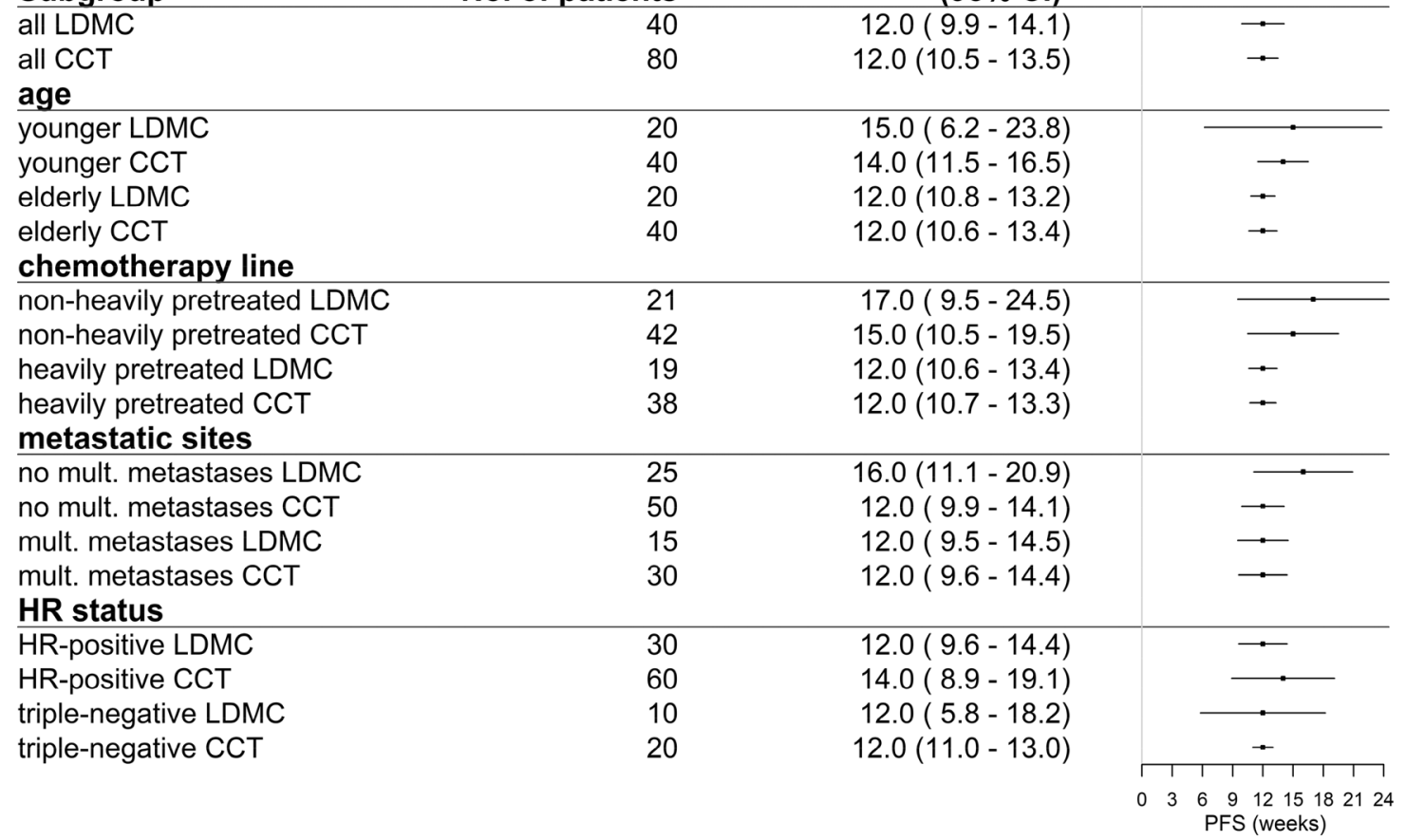

Fig. 2 a Disease control rate in subgroups. b Median progression-free survival in subgroups. c Hazard ratio for progression or death in subgroups 
Hazard ratio for

progression or death

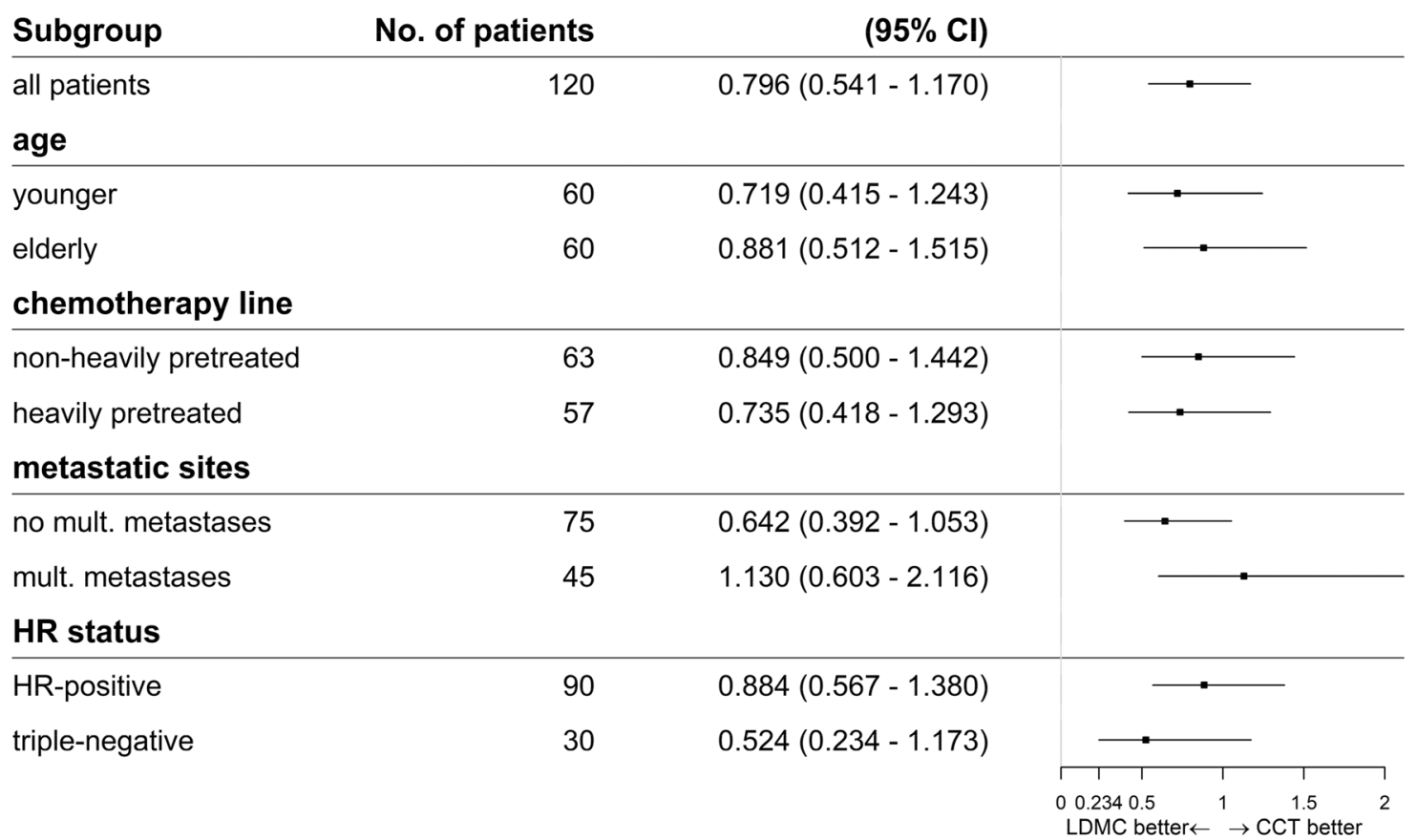

Fig. 2 (continued)

of QoL of patients and reduced healthcare costs as well as having benefits over intravenous administration such as prolonged plasma drug concentration or increased therapeutic window makes LDMC attractive in clinical practice [31, 32]. Apart from that there are still several aspects that need to be clarified, such as patient selection, the choice of cytotoxic drug used for treatment, its optimal dose and decision between single versus doublet agent administration [8,33]. Nevertheless, based on previous studies, LDMC represents a therapy option for MBC patients without need for rapid response and can be recommended according to the Breast Committee of the German Gynecological Oncology Working Group in HR-positive, HER2-negative MBC patients after anthracycline and taxane pretreatment $[34,35]$. In addition to HR-positive patients, we demonstrated a favorable effect also in the triple-negative subgroup. Considering that, the therapeutic goal in advanced disease is on the one hand to maintain the QoL and on the other hand to control the disease, LDMC is a valuable option. It may be administered particularly in asymptomatic patients with endocrine resistance and triple-negative disease to prolong PFS and delay the onset of the often more toxic CCT with MTD regimen. Furthermore, combination of LDMC with antiangiogenic and immunomodulatory substances seems to be promising [36-40]. Further analyses are needed to gain detailed experience about the role of LDMC in the management of MBC, including QoL issues and combination therapies with e.g. immunomodulatory drugs.

To the best of our knowledge, the presented analyses are the first to compare and show a similar efficacy of LDMC and CCT in terms of age, previous chemotherapy and severity of metastatic lesions. However, the retrospective character limits the validity of the presented data. In particular, since the median age at first diagnosis MBC was 59 for both groups and the median age at start of therapy was 63 in LDMC and 61 in CCT group, it can be assumed that LDMC patients had a less aggressive disease and/or better response to prior therapies compared to CCT patients. Reliable information on the toxicity of the administered therapies is not presented. Moreover, the validity of our conclusions is impaired by the study design and should be regarded as hypothesis generating. Therefore, we try to overcome this limitation and prepare a prospective non-interventional study to gather further insights about LDMC in MBC regarding patient-reported outcome, QoL, safety and efficacy, named PROmetronomic.

In conclusion, in our retrospective case-control study we could demonstrate a similar efficacy of LDMC compared to CCT in the treatment of MBC. Our analyses support further efforts to investigate the LDMC in selected MBC patients. 
Acknowledgements Open Access funding provided by Projekt DEAL. Parts of the presented results were from the doctoral thesis of Ms. Carola Schnatz.

Funding No funding was received.

\section{Compliance with ethical standards}

Conflict of interest All other authors declare that they have no conflict of interest. S. Krajnak received speaker honoraria from Roche Pharma AG. He received research funding from Novartis and travel reimbursement from PharmaMar. K. Almstedt received speaker honoraria from Roche Pharma AG, Pfizer Pharma GmbH and AstraZeneca. R.Schwab received speaker honoraria from Roche Pharma AG and AstraZeneca. A. Hasenburg received honoraria from AstraZeneca, Celegen, MedConcept Gm, Med update GmbH, Medicultus, Pfizer, Promedicis GmbH, Pierre Fabre, Softconsult, Roche Pharma AG, Streamedup! GmbH and Tesaro Bio Germany GmbH. She is a member of the advisory board of PharmaMar, Promedicis GmbH, Pierre Fabre Pharma GmbH, Roche Pharma AG and Tesaro Bio Germany GmbH. She received research funding from Celgene. M. Schmidt received honoraria for speaker or consultancy role from AMGEN, AstraZeneca, Eisai, Lilly, Myelo Therapeutics, Novartis, Pantarhei Bioscience, Pfizer, and Roche Pharma AG. He received research funding from AstraZeneca, BioNTech, Eisai, Genentech, Myelo Therapeutics, Novartis, Pantarhei Bioscience, Pfizer, Pierre-Fabre, and Roche. He received travel reimbursement from Pfizer and Roche Pharma AG. M.J. Battista received honoraria for speaker or consultancy role from AstraZenca, MSD, PharmaMar, Roche Pharma AG, TEVA and Tesaro. He received travel reimbursement from Celgene, PharmaMar and Pierre Fabre.

Ethical approval All procedures performed in studies involving human participants were in accordance with the ethical standards of the institutional and/or national research committee and with the 1964 Helsinki declaration and its later amendments or comparable ethical standards.

Informed consent Informed consent was obtained from all individual participants included in the study.

Open Access This article is licensed under a Creative Commons Attribution 4.0 International License, which permits use, sharing, adaptation, distribution and reproduction in any medium or format, as long as you give appropriate credit to the original author(s) and the source, provide a link to the Creative Commons licence, and indicate if changes were made. The images or other third party material in this article are included in the article's Creative Commons licence, unless indicated otherwise in a credit line to the material. If material is not included in the article's Creative Commons licence and your intended use is not permitted by statutory regulation or exceeds the permitted use, you will need to obtain permission directly from the copyright holder. To view a copy of this licence, visit http://creativecommons.org/licenses/by/4.0/.

\section{References}

1. Cardoso F, Senkus E, Costa A, Papadopoulos E, Aapro M, Andre F, Harbeck N, Aguilar Lopez B, Barrios CH, Bergh J, Biganzoli L, Boers-Doets CB, Cardoso MJ, Carey LA, Cortes J, Curigliano G, Dieras V, El Saghir NS, Eniu A, Fallowfield L, Francis PA, Gelmon K, Johnston SRD, Kaufman B, Koppikar S, Krop IE, Mayer M, Nakigudde G, Offersen BV, Ohno S, Pagani O, Paluch-Shimon S, Penault-Llorca F, Prat A, Rugo HS, Sledge GW,
Spence D, Thomssen C, Vorobiof DA, Xu B, Norton L, Winer EP (2018) 4th ESO-ESMO International Consensus Guidelines for Advanced Breast Cancer (ABC 4)dagger. Ann Oncol 29(8):16341657. https://doi.org/10.1093/annonc/mdy 192

2. Cazzaniga ME, Pinotti G, Montagna E, Amoroso D, Berardi R, Butera A, Cagossi K, Cavanna L, Ciccarese M, Cinieri S, Cretella E, De Conciliis E, Febbraro A, Ferrau F, Ferzi A, Fiorentini G, Fontana A, Gambaro AR, Garrone O, Gebbia V, Generali D, Gianni L, Giovanardi F, Grassadonia A, Leonardi V, Marchetti P, Melegari E, Musolino A, Nicolini M, Putzu C, Riccardi F, Santini D, Saracchini S, Sarobba MG, Schintu MG, Scognamiglio G, Spadaro P, Taverniti C, Toniolo D, Tralongo P, Turletti A, Valenza R, Valerio MR, Vici P, Clivio L, Torri V, Group VS (2019) Metronomic chemotherapy for advanced breast cancer patients in the real world practice: final results of the VICTOR-6 study. Breast 48:7-16. https://doi.org/10.1016/j.breast.2019.07.006

3. Simsek C, Esin E, Yalcin S (2019) Metronomic Chemotherapy: A Systematic Review of the Literature and Clinical Experience. J Oncol 2019:5483791. https://doi.org/10.1155/2019/5483791

4. Hanahan D, Bergers G, Bergsland E (2000) Less is more, regularly: metronomic dosing of cytotoxic drugs can target tumor angiogenesis in mice. J Clin Invest 105(8):1045-1047. https:// doi.org/10.1172/JCI9872

5. Colleoni M, Rocca A, Sandri MT, Zorzino L, Masci G, Nole F, Peruzzotti G, Robertson C, Orlando L, Cinieri S, Viale BF, Goldhirsch G (2002) Low-dose oral methotrexate and cyclophosphamide in metastatic breast cancer: antitumor activity and correlation with vascular endothelial growth factor levels. Ann Oncol 13(1):73-80

6. Gebbia V, Boussen H, Valerio MR (2012) Oral metronomic cyclophosphamide with and without methotrexate as palliative treatment for patients with metastatic breast carcinoma. Anticancer Res 32(2):529-536

7. Perroud HA, Alasino CM, Rico MJ, Mainetti LE, Queralt F, Pezzotto SM, Rozados VR, Scharovsky OG (2016) Metastatic breast cancer patients treated with low-dose metronomic chemotherapy with cyclophosphamide and celecoxib: clinical outcomes and biomarkers of response. Cancer Chemother Pharmacol 77(2):365374. https://doi.org/10.1007/s00280-015-2947-9

8. Cazzaniga ME, Munzone E, Bocci G, Afonso N, Gomez P, Langkjer S, Petru E, Pivot X, Sanchez Rovira P, Wysocki P, Torri V (2019) Pan-European Expert Meeting on the Use of Metronomic Chemotherapy in Advanced Breast Cancer Patients: The PENELOPE Project. Adv Ther 36(2):381-406. https://doi.org/10.1007/ s12325-018-0844-4

9. Schmidt M (2016) Dose-Dense Chemotherapy in Metastatic Breast Cancer: Shortening the Time Interval for a Better Therapeutic Index. Breast Care (Basel) 11(1):22-26. https://doi. org/10.1159/000442726

10. Krajnak S, Battista M, Brenner W, Almstedt K, Elger T, Heimes AS, Hasenburg A, Schmidt M (2018) Explorative Analysis of Low-Dose Metronomic Chemotherapy with Cyclophosphamide and Methotrexate in a Cohort of Metastatic Breast Cancer Patients. Breast Care (Basel) 13(4):272-276. https://doi. org/10.1159/000487629

11. Aurilio G, Munzone E, Botteri E, Sciandivasci A, Adamoli L, Minchella I, Esposito A, Cullura D, Curigliano G, Colleoni M, Goldhirsch A, Nole F (2012) Oral metronomic cyclophosphamide and methotrexate plus fulvestrant in advanced breast cancer patients: a mono-institutional case-cohort report. Breast $\mathbf{J}$ 18(5):470-474. https://doi.org/10.1111/j.1524-4741.2012.01278.x

12. Colleoni M, Orlando L, Sanna G, Rocca A, Maisonneuve P, Peruzzotti G, Ghisini R, Sandri MT, Zorzino L, Nole F, Viale G, Goldhirsch A (2006) Metronomic low-dose oral cyclophosphamide and methotrexate plus or minus thalidomide in metastatic 
breast cancer: antitumor activity and biological effects. Ann Oncol 17(2):232-238. https://doi.org/10.1093/annonc/mdj066

13. Li JW, Zuo WJ, Ivanova D, Jia XQ, Lei L, Liu GY (2019) Metronomic capecitabine combined with aromatase inhibitors for new chemoendocrine treatment of advanced breast cancer: a phase II clinical trial. Breast Cancer Res Treat 173(2):407-415. https://doi. org/10.1007/s10549-018-5024-3

14. Romiti A, Falcone R, Roberto M, Marchetti P (2016) Current achievements and future perspectives of metronomic chemotherapy. Invest New Drugs. https://doi.org/10.1007/s1063 7-016-0408-X

15. Liu Y, Gu F, Liang J, Dai X, Wan C, Hong X, Zhang K, Liu L (2017) The efficacy and toxicity profile of metronomic chemotherapy for metastatic breast cancer: a meta-analysis. PLoS ONE 12(3):e0173693. https://doi.org/10.1371/journal.pone.0173693

16. Cazzaniga ME, Biganzoli L, Cortesi L, De Placido S, Donadio M, Fabi A, Ferro A, Generali D, Lorusso V, Milani A, Montagna E, Munzone E, Orlando L, Pizzuti L, Simoncini E, Zamagni C, Pappagallo GL, Metronomic Chemotherapy in Advanced Breast Cancer" Study G (2019) Treating advanced breast cancer with metronomic chemotherapy: what is known, what is new and what is the future? Onco Targets Ther 12:2989-2997. https://doi. org/10.2147/OTT.S189163

17. Montagna E, Palazzo A, Maisonneuve P, Cancello G, Iorfida M, Sciandivasci A, Esposito A, Cardillo A, Mazza M, Munzone E, Lai A, Goldhirsch A, Colleoni M (2017) Safety and efficacy study of metronomic vinorelbine, cyclophosphamide plus capecitabine in metastatic breast cancer: A phase II trial. Cancer Lett 400:276281. https://doi.org/10.1016/j.canlet.2017.01.027

18. Addeo R, Sgambato A, Cennamo G, Montella L, Faiola V, Abbruzzese A, Capasso E, Leo L, Botti G, Caraglia M, Del Prete S (2010) Low-dose metronomic oral administration of vinorelbine in the first-line treatment of elderly patients with metastatic breast cancer. Clin Breast Cancer 10(4):301-306. https://doi. org/10.3816/CBC.2010.n.039

19. Yoshimoto M, Takao S, Hirata M, Okamoto Y, Yamashita S, Kawaguchi Y, Takami M, Furusawa H, Morita S, Abe C, Sakamoto J (2012) Metronomic oral combination chemotherapy with capecitabine and cyclophosphamide: a phase II study in patients with HER2-negative metastatic breast cancer. Cancer Chemother Pharmacol 70(2):331-338. https://doi.org/10.1007/s0028 0-012-1826-x

20. Dufresne A, Pivot X, Tournigand C, Facchini T, Altweegg T, Chaigneau L, De Gramont A (2008) Impact of chemotherapy beyond the first line in patients with metastatic breast cancer. Breast Cancer Res Treat 107(2):275-279. https://doi.org/10.1007/ s10549-007-9550-7

21. Cazzaniga ME, Cortesi L, Ferzi A, Scaltriti L, Cicchiello F, Ciccarese M, Della Torre S, Villa F, Giordano M, Verusio C, Nicolini M, Gambaro AR, Zanlorenzi L, Biraghi E, Legramandi L, Rulli E, Group VS (2016) Metronomic chemotherapy with oral vinorelbine (mVNR) and capecitabine (mCAPE) in advanced HER2-negative breast cancer patients: is it a way to optimize disease control? Final results of the VICTOR-2 study. Breast Cancer Res Treat 160(3):501-509. https://doi.org/10.1007/s10549-016-4009-3

22. Lu Q, Lee K, Xu F, Xia W, Zheng Q, Hong R, Jiang K, Zhai Q, Li Y, Shi Y, Yuan Z, Wang S (2020) Metronomic chemotherapy of cyclophosphamide plus methotrexate for advanced breast cancer: real-world data analyses and experience of one center. Cancer Commun (Lond). https://doi.org/10.1002/cac2.12029

23. Thill M, Liedtke C, Muller V, Janni W, Schmidt M, Committee AGOB (2018) AGO recommendations for the diagnosis and treatment of patients with advanced and metastatic breast cancer: update 2018. Breast Care (Basel) 13(3):209-215. https://doi. org $/ 10.1159 / 000489331$
24. Harbeck N, Gnant M (2017) Breast cancer. Lancet 389(10074):1134-1150. https://doi.org/10.1016/S0140 $-6736(16) 31891-8$

25. Masoud V, Pages G (2017) Targeted therapies in breast cancer: New challenges to fight against resistance. World J Clin Oncol 8(2):120-134. https://doi.org/10.5306/wjco.v8.i2.120

26. Murphy CG (2019) The Role of CDK4/6 inhibitors in breast cancer. Curr Treat Options Oncol 20(6):52. https://doi.org/10.1007/ s11864-019-0651-4

27. Andre N, Tsai K, Carre M, Pasquier E (2017) Metronomic chemotherapy: direct targeting of cancer cells after all? Trends Cancer 3(5):319-325. https://doi.org/10.1016/j.trecan.2017.03.011

28. Kerbel RS, Shaked Y (2017) The potential clinical promise of 'multimodality' metronomic chemotherapy revealed by preclinical studies of metastatic disease. Cancer Lett 400:293-304. https:// doi.org/10.1016/j.canlet.2017.02.005

29. Munoz R, Hileeto D, Cruz-Munoz W, Wood GA, Xu P, Man S, Viloria-Petit A, Kerbel RS (2019) Suppressive impact of metronomic chemotherapy using UFT and/or cyclophosphamide on mediators of breast cancer dissemination and invasion. PLoS ONE 14(9):e0222580. https://doi.org/10.1371/journal.pone.0222580

30. Kareva I, Waxman DJ, Lakka Klement G (2015) Metronomic chemotherapy: an attractive alternative to maximum tolerated dose therapy that can activate anti-tumor immunity and minimize therapeutic resistance. Cancer Lett 358(2):100-106. https://doi. org/10.1016/j.canlet.2014.12.039

31. Bocci G, Tuccori M, Emmenegger U, Liguori V, Falcone A, Kerbel RS, Del Tacca M (2005) Cyclophosphamide-methotrexate 'metronomic' chemotherapy for the palliative treatment of metastatic breast cancer. A comparative pharmacoeconomic evaluation Ann Oncol 16(8):1243-1252. https://doi.org/10.1093/annon c/mdi240

32. Thanki K, Gangwal RP, Sangamwar AT, Jain S (2013) Oral delivery of anticancer drugs: challenges and opportunities. J Control Release 170(1):15-40. https://doi.org/10.1016/j.jconr el.2013.04.020

33. Lien K, Georgsdottir S, Sivanathan L, Chan K, Emmenegger U (2013) Low-dose metronomic chemotherapy: a systematic literature analysis. Eur J Cancer 49(16):3387-3395. https://doi. org/10.1016/j.ejca.2013.06.038

34. Thill M, Jackisch C, Janni W, Muller V, Albert US, Bauerfeind I, Blohmer J, Budach W, Dall P, Diel I, Fasching PA, Fehm T, Friedrich M, Gerber B, Hanf V, Harbeck N, Huober J, KolbergLiedtke C, Kreipe HH, Krug D, Kuhn T, Kummel S, Loibl S, Luftner D, Lux MP, Maass N, Mobus V, Muller-Schimpfle M, Mundhenke C, Nitz U, Rhiem K, Rody A, Schmidt M, Schneeweiss A, Schutz F, Sinn HP, Solbach C, Solomayer EF, Stickeler E, Thomssen C, Untch M, Wenz F, Witzel I, Wockel A, Ditsch N (2019) AGO Recommendations for the Diagnosis and Treatment of Patients with Locally Advanced and Metastatic Breast Cancer: Update 2019. Breast Care (Basel) 14(4):247-255. https ://doi.org/10.1159/000500999

35. Thomssen C, Luftner D, Untch M, Haidinger R, Wurstlein R, Harbeck N, Augustin D, Briest S, Ettl J, Fasching PA, Forster F, Kurbacher CM, Luck HJ, Marschner N, Muller L, Muller V, Perlova-Griff L, Radke I, Ruckhaberle E, Scheffen I, SchumacherWulf E, Schwoerer M, Steinfeld-Birg D, Ziegler-Lohr K (2020) International Consensus Conference for Advanced Breast Cancer, Lisbon 2019: ABC5 Consensus - Assessment by a German Group of Experts. Breast Care (Basel) 15(1):82-95. https://doi. org/10.1159/000505957

36. Hao YB, Yi SY, Ruan J, Zhao L, Nan KJ (2014) New insights into metronomic chemotherapy-induced immunoregulation. Cancer Lett 354(2):220-226. https://doi.org/10.1016/j.canlet.2014.08.028

37. Kareva I (2017) A Combination of Immune Checkpoint Inhibition with Metronomic Chemotherapy as a Way of 
Targeting Therapy-Resistant Cancer Cells. Int J Mol Sci. https:// doi.org/10.3390/ijms18102134

38. Mayer EL, Isakoff SJ, Klement G, Downing SR, Chen WY, Hannagan K, Gelman R, Winer EP, Burstein HJ (2012) Combination antiangiogenic therapy in advanced breast cancer: a phase 1 trial of vandetanib, a VEGFR inhibitor, and metronomic chemotherapy, with correlative platelet proteomics. Breast Cancer Res Treat 136(1):169-178. https://doi.org/10.1007/s10549-012-2256-5

39. Petrizzo A, Mauriello A, Luciano A, Rea D, Barbieri A, Arra C, Maiolino P, Tornesello M, Gigantino V, Botti G, Ciliberto G, Buonaguro FM, Tagliamonte M, Buonaguro L (2018) Inhibition of tumor growth by cancer vaccine combined with metronomic chemotherapy and anti-PD-1 in a pre-clinical setting. Oncotarget 9(3):3576-3589. https://doi.org/10.18632/oncotarget.23181

40. Rochlitz C, Bigler M, von Moos R, Bernhard J, Matter-Walstra K, Wicki A, Zaman K, Anchisi S, Kung M, Na KJ, Bartschi D,
Borner M, Rordorf T, Rauch D, Muller A, Ruhstaller T, Vetter M, Trojan A, Hasler-Strub U, Cathomas R, Winterhalder R (2016) SAKK 24/09: safety and tolerability of bevacizumab plus paclitaxel vs. bevacizumab plus metronomic cyclophosphamide and capecitabine as first-line therapy in patients with HER2-negative advanced stage breast cancer - a multicenter, randomized phase III trial. BMC Cancer 16(1):780. https://doi.org/10.1186/s1288 5-016-2823-y

Publisher's Note Springer Nature remains neutral with regard to jurisdictional claims in published maps and institutional affiliations. 